\title{
Hypoxia and Inflammation
}

Holger K. Eltzschig, M.D., Ph.D. and Peter Carmeliet, M.D., Ph.D. Department of Anesthesiology, University of Colorado Denver, Aurora (H.K.E.); the Department of Anesthesiology and Intensive Care Medicine, Tübingen University Hospital, Tübingen, Germany (H.K.E.); and Vesalius Research Center VIB, and Vesalius Research Center, K.U. Leuven - both in Leuven, Belgium (P.C.)

Mammals have oxygen-sensing mechanisms that help them adapt quickly to hypoxia by increasing respiration, blood flow, and survival responses. If an inadequate supply of oxygen persists, additional mechanisms attempt to restore oxygenation or help the body adapt to hypoxia. ${ }^{1}$ These other mechanisms rely on oxygen-sensing prolyl hydroxylases (PHDs), which hydroxylate prolines in the alpha subunit of the hypoxia-inducible transcription factor (HIF). This transcription factor is a heterodimer with two subunits: HIF-1 $a$ or HIF-2 $a$ and HIF- $1 \beta$ (or aryl hydrocarbon receptor nuclear translocator [ARNT] protein). HIF- $1 a$ is ubiquitous, whereas HIF- $2 a$ is restricted to certain tissues. ${ }^{1}$

In this review, we show the ways in which the PHD-HIF system affects inflammatory processes. We discuss the regulation of immune responses by hypoxia-induced signaling, outline molecular aspects of the cross-talk between hypoxia and inflammation, and illustrate the link between hypoxia and inflammation in inflammatory bowel disease, certain cancers, and infections.

\section{HYPOXIA-INDUCED INFLAMMATION}

The concept that hypoxia can induce inflammation has gained general acceptance from studies of the hypoxia signaling pathway. In persons with mountain sickness, for example, levels of circulating proinflammatory cytokines increase, and leakage of fluid ("vascular leakage") causes pulmonary or cerebral edema. ${ }^{1-3}$ Increased serum levels of interleukin-6, the interleukin-6 receptor, and C-reactive protein — all markers of inflammation - were increased in healthy volunteers who spent 3 nights at an elevation higher than $3400 \mathrm{~m} .{ }^{4}$ At $8400 \mathrm{~m}$, healthy climbers ascending Mount Everest had severe hypoxemia (partial pressure of arterial oxygen $\left[\mathrm{PaO}_{2}\right], 25 \mathrm{~mm} \mathrm{Hg}$ ). Alveolar-arterial oxygen differences were elevated in these climbers, a finding that is consistent with subclinical high-altitude pulmonary edema. ${ }^{3}$ Moreover, vascular leakage, accumulations of inflammatory cells in multiple organs, and elevated serum levels of cytokines occur in mice after short-term exposure to low oxygen concentrations. ${ }^{5-9}$

The development of inflammation in response to hypoxia is clinically relevant. Ischemia in organ grafts increases the risk of inflammation and graft failure or rejection. ${ }^{10}$ In patients undergoing kidney transplantation, the renal expression of toll-like receptor (TLR) 4 - an extracellular receptor for bacterial lipopolysaccharide — was shown to correlate with the degree of ischemic injury. In this study, donor kidneys with a loss-of-function TLR4 allele,

Copyright @ 2011 Massachusetts Medical Society.

Address reprint requests to Dr. Eltzschig at the Department of Anesthesiology, University of Colorado Denver, 12700 E. 19 th Ave., Mailstop B112, Research Complex 2, Rm. 7124, Aurora, CO 80045, or at holger.eltzschig@ucdenver.edu.

Disclosure forms provided by the authors are available with the full text of this article at NEJM.org. 
as compared with donor kidneys that bore a functional allele of the TLR4 gene, had a higher rate of immediate graft function. ${ }^{10}$ Moreover, increases in pulmonary cytokine levels and TLR expression was shown to correlate with greater ischemic injury of transplanted lungs and loss of graft function. ${ }^{11,12}$ In the setting of obesity, an imbalance between the supply of and demand for oxygen in enlarged adipocytes causes tissue hypoxia and an increase in inflammatory adipokines in fat. The resultant infiltration by macrophages and chronic lowgrade systemic inflammation promote insulin resistance. ${ }^{13}$ Taken together, these clinical studies indicate that hypoxia promotes inflammation (Fig. 1).

\section{INFLAMMATION AND TISSUE HYPOXIA}

Just as hypoxia can induce inflammation, inflamed lesions often become severely hypoxic. As a result of the steep oxygen gradient between the anaerobic intestinal lumen and the metabolically active lamina propria mucosae, intestinal epithelial cells are normally hypoxic. ${ }^{14}$ In inflammatory bowel disease, not only does the entire mucosa becomes even more hypoxic, ${ }^{14}$ but surgical specimens of the inflamed intestine contain elevated levels of HIF- $1 a$ and HIF- $2 a .{ }^{15}$

Contributors to tissue hypoxia during inflammation include an increase in the metabolic demands of cells and a reduction in metabolic substrates caused by thrombosis, trauma, compression (interstitial hypertension), or atelectasis (airway plugging). Moreover, multiplication of intracellular pathogens can deprive infected cells of oxygen. ${ }^{16} \mathrm{We}$ stress that in the case of inflamed tissue, hypoxia is not a bystander but instead can influence the environment of the tissue, particularly by regulating oxygen-dependent gene expression.

\section{HIF AND OXYGEN SENSORS}

Cellular adaptations to hypoxia rely on the transcription factor HIF, which is inactive when oxygen is abundant but is activated in hypoxic conditions (Fig. 2). ${ }^{1,17}$ Oxygen-dependent hydroxylation of prolyl residues in HIF- $1 a$ or HIF- $2 a$ in the HIF heterodimer by PHDs creates a binding site for the von Hippel-Lindau (VHL) gene product, which is a component of the E3 ubiquitin ligase complex; the binding of the VHL gene product to HIF-1 $a$ (or HIF-2 $a$ ) culminates in the destruction of the $a$ subunit in proteasomes. ${ }^{18}$ In addition, hydroxylation of asparagyl residues in HIF- $1 a$ (or HIF- $2 a$ ) by factor-inhibiting HIF - an oxygen-dependent asparagyl hydroxylase - reduces the transcriptional activity of HIF. ${ }^{19}$ The functions of both hydroxylases (PHDs and factor-inhibiting HIF) depend on oxygen. ${ }^{1,17}$ Germline mutations in the PHD2 gene have been found in association with familial erythrocytosis and with a syndrome of familial erythrocytosis with paraganglioma ${ }^{20}$; inactivating mutations of both copies of the VHL gene cause Von Hippel-Lindau disease (which is characterized by hemangioblastomas, clear-cell renal carcinomas, and pheochromocytomas). ${ }^{18}$

HIF can be activated under normoxic conditions, which allows the initiation of an inflammatory response before tissues become hypoxic. Examples of this mechanism are the increase in HIF-1 $a$ transcription by bacterial lipopolysaccharide ${ }^{21}$ and the stabilization of HIF- $1 a$ when reactive oxygen species and reduced cellular iron inhibit prolyl hydroxylase. ${ }^{22,23}$

The phenotype of mice with HIF- $1 a$ deficiency differs from that of mice with HIF- $2 a$ deficiency, which implies that these components of the HIF transcription-factor polypeptides have different target genes. ${ }^{24}$ The HIF2A gene in certain forms of familial erythrocytosis has a gain-of-function mutation, which probably causes normoxic stabilization of the HIF- $2 a$ protein. ${ }^{25}$ 


\section{HYPOXIA SIGNALING AND NF- $K B$}

Members of the nuclear factor $k \mathrm{~B}(\mathrm{NF}-k \mathrm{~B})$ family of transcription factors regulate inflammation and orchestrate immune responses and tissue homeostasis. ${ }^{26-28}$ Members of this family interact with members of the PHD-HIF pathway in ways that link inflammation to hypoxia (Fig. 2). ${ }^{29}$ Studies of a mouse model of inflammatory bowel disease indicate that PHDs have a regulatory role in the antiapoptotic effects of NF- $k$ B in intestinal inflammation. ${ }^{30,31}$ The hypoxia of intestinal ischemia reperfusion activates NF- $\kappa \mathrm{B}$ in intestinal epithelial cells, which in turn increases the production of tumor necrosis factor $a$ (TNF- $\alpha$ ), a proinflammatory cytokine, but simultaneously attenuates intestinal epithelial apoptosis. ${ }^{32}$ Additional interactions between hypoxia and inflammation are seen in the $\mathrm{I} k \mathrm{~B}$ kinase complex, a regulatory component of NF- $k$ B (Fig. 2), ${ }^{30}$ and in the regulation of HIF- $1 a$ transcription by NF- $\kappa$ B before and during inflammation. ${ }^{33,34}$ Hypoxia amplifies the NF- $k \mathrm{~B}$ pathway by increasing the expression and signaling of TLRs, which enhance the production of antimicrobial factors and stimulate phagocytosis, leukocyte recruitment, and adaptive immunity. ${ }^{35}$

\section{HYPOXIA SIGNALING AND INNATE IMMUNITY}

The initial defense against pathogens relies on the activation of neutrophils, macrophages, mast cells, dendritic cells, and natural killer cells. These cells of the innate immune system can rapidly eradicate pathogens and transmit signals that amplify the adaptive immune response. Myeloid cells have HIF-dependent ways of functioning in the oxygen-depleted conditions of hypoxic microenvironments. ${ }^{36} \mathrm{HIF}-1 a$-null phagocytes cannot efficiently eliminate bacterial loads but instead form persistent ulcerative lesions. ${ }^{36,37}$

HIF-1 $a$ regulates several functions of myeloid cells (Fig. 3).$^{38}$ It allows myeloid cells to generate ATP in oxygen-deprived inflamed tissues, thereby stimulating the aggregation, motility, invasiveness, and bactericidal activity of myeloid cells. ${ }^{36,37} \mathrm{HIF}-1 a$ also prolongs the lifespan of neutrophils in hypoxic conditions by inhibiting apoptosis. ${ }^{39}$ In von HippelLindau disease, neutrophils are characterized by reduced apoptosis and enhanced phagocytosis of bacteria under normoxic conditions, presumably owing to the failure to degrade HIF- $1 a .^{40}$

\section{HYPOXIA AND ADAPTIVE IMMUNITY}

HIF-1 $a$ also influences adaptive immunity. ${ }^{41}$ Mice with HIF-1 $a$-deficient lymphocytes have elevated levels of anti-double-stranded DNA antibodies and rheumatoid factor in serum, as well as proteinuria and deposits of $\operatorname{IgG}$ and IgM in the kidney. ${ }^{42}$ Increased production of HIF-1 $a$ in T cells induces a shift from a type 1 helper T-cell (Th1) phenotype, which enhances functions of macrophages and cytotoxic T cells, to a type 2 helper T-cell (Th2) phenotype, which inhibits Th1-mediated microbicidal actions of T cells by increasing production of interleukin-10 and decreasing interferon- $\gamma$ levels. ${ }^{43} \mathrm{HIF}$ also influences regulatory T cells, ${ }^{44}$ a specialized subgroup of inhibitory T cells. ${ }^{45}$ Hypoxia-induced signaling pathways stimulate the differentiation and proliferation of regulatory $\mathrm{T}$ cells $\mathrm{s}^{44}$ and increase extracellular levels of adenosine,${ }^{46}$ which protects tissues by restraining effector functions of T cells. ${ }^{47}$

\section{EPITHELIAL RESPONSES TO HYPOXIC INFLAMMATION}

Activation of the PHD-HIF pathway promotes the resolution of mucosal inflammation in mice. ${ }^{48}$ Hypoxia-induced changes in gene expression by epithelial cells help to promote mucosal barrier function (e.g., through activation of intestinal trefoil factor) ${ }^{49}$ or to increase the production by the epithelium of antiinflammatory signaling molecules such as 
adenosine.$^{50}$ These adaptive responses to hypoxia are activated during mucosal inflammation and promote the resolution of inflammatory bowel disease ${ }^{14,51-53}$ or acute lung injury. ${ }^{5,6,54-58}$ In mice with targeted deletion of HIF- $1 a$ in intestinal epithelia, as compared with mice that have intact HIF-1 $a$ throughout, more severe colitis develops after exposure to trinitrobenzene sulfonic acid. In contrast, in mice with inflammatory bowel disease and elevated HIF levels due to deficiency of the VHL gene, as compared with control animals, weight loss, disease activity, and histologic signs of intestinal inflammation are all reduced. ${ }^{14}$ In mice with colitis that is chemically induced by oral administration of dextran sulfate sodium, treatment with pharmacologic compounds that enhance stabilization of HIF reduces intestinal inflammation. ${ }^{51,52}$

Several studies have shown that hypoxia enhances the enzymatic conversion of precursor nucleotides such as ATP, adenosine diphosphate, or AMP to adenosine, ${ }^{7,59}$ thereby elevating extracellular levels of adenosine, an antiinflammatory signaling molecule involved in restraining innate immune responses. ${ }^{54,60} \mathrm{~A}$ single-nucleotide polymorphism in CD39, an enzyme required for extracellular generation of adenosine, is associated with low levels of $\mathrm{CD} 39^{61}$; in a case-control study, this genetic variant was observed in patients with Crohn's disease more frequently than it was seen in healthy subjects. ${ }^{61}$

HIF stimulates the production of extracellular adenosine ${ }^{62,63}$ and suppresses both its uptake into the intracellular compartment and its intracellular metabolism. ${ }^{64,65} \mathrm{HIF}$ also enhances adenosinereceptor signaling by increasing the expression on the cell surface of adenosine receptors $63,66,67$ - an effect that attenuates immune responses, vascular fluid leakage, and neutrophil accumulation in the presence of myocardial, renal, hepatic, or intestinal ischemia or acute lung injury. ${ }^{50,56,68,69}$ HIF-dependent induction of the axon guidance signal netrin-1 in epithelia interferes with the entry of inflammatory cells into hypoxic organs by enhancing extracellular adenosine signaling events. ${ }^{5}$ Other studies have shown that HIF also attenuates epithelial inflammation through induction of epithelial decay-accelerating factor (which clears epithelia from neutrophils) ${ }^{70}$ and induction of barrier-protective genes in the case of experimentally induced colitis or hypoxia. ${ }^{14,49}$

\section{CANCER}

Concentrations of oxygen in solid tumors, as compared with those in normal tissues, are frequently reduced. ${ }^{71}$ Solid tumors contain increased levels of HIF-1 $a$ and HIF-2 $a$, and these elevated levels correlate with cancer-related death. ${ }^{71}$ Elevated levels of HIF-1 $\alpha$ and HIF- $2 a$ in biopsy specimens of prostate tumors have been associated with an adverse clinical course. ${ }^{72}$ Hypoxia in a solid tumor stabilizes HIF through hypoxia-dependent inhibition of PHDs. Similarly, oncogenes, or the loss of function of tumor-suppressor genes, result in the stabilization of HIF, as happens in the case of the VHL tumor-suppressor gene. In von Hippel-Lindau disease, inactivating germline mutations of the VHL tumorsuppressor gene increase the risk of renal-cell carcinoma and other tumors. ${ }^{73}$ Hypoxia and inflammation meet at several points in the setting of cancer (Fig. 4). Activation of HIF in a hypoxic tumor or in stromal cells within the tumor augments tumor vascularization. ${ }^{24,74}$ This increase in vascularization changes the morphologic characteristics of tumor vessels and their endothelial lining in ways that compromise oxygen delivery. ${ }^{75}$ Inflammatory cells also contribute to anomalies of vessels in tumors by releasing vascular endothelial growth factor.

In mice, haplodeletion of PHD2 attenuates tumor-vessel leakiness and vascular distortion while improving tumor-vessel architecture ("vascular normalization," as defined by more sharply demarcated boundaries and branching points of tumor vessels ${ }^{76}$ and tumor oxygenation. ${ }^{77}$ This change is associated with a reduction in tumor invasiveness and in the 
risk of metastasis. ${ }^{77}$ This finding suggests that endothelial cells use PHDs to sense and correct imbalances in oxygen delivery. Anti-PHD2 agents may offer a new approach to treating cancer, since they improve the architecture and function of tumor vessels. ${ }^{78}$

Experimental evidence indicates that inhibition of HIF within the inflamed tumor core attenuates the growth and vascularization of tumors and enhances the sensitivity of tumors to radiation. ${ }^{79}$ In contrast, inhibition of PHD2 and stabilization of HIF within the tumor vasculature may play an important role in tumor therapy, if the means can be found to selectively direct inhibitors of PHD to the tumor vasculature and inhibitors of HIF to the hypoxic core.

\section{INFECTIONS}

Stabilization of HIF and induction of HIF-dependent genes occur during infections with pathogens. For example, infection with Bartonella henselae - the causative agent of bacillary angiomatosis - is associated with stabilization of HIF- $1 a$ and the transcription of genes that typically become transcribed in hypoxic conditions. ${ }^{16}$ In infected cells, changes in oxygen consumption, as well as cellular hypoxia and decreased ATP levels, correlate with HIF stabilization and the release of angiogenic factors during bacillary angiomatosis. ${ }^{16}$ Stabilization of HIF during infections can also be oxygen-independent. ${ }^{80}$ For example, under normoxic conditions, iron uptake by bacteria attenuates PHD activity, stabilizes HIF- $1 a$, and induces the expression of genes targeted by HIF. ${ }^{81-83}$ Stabilization of HIF- $1 a$ has been found in liver-biopsy specimens obtained from patients with chronic hepatitis $\mathrm{C}^{84}$ and in skin-biopsy specimens obtained from patients with cutaneous infections caused by Staphylococcus aureus, varicella-zoster virus, human herpesvirus 8 , or Candida albicans. ${ }^{85}$

Pathogens may highjack the host's HIF pathway for their own advantage. Pseudomonas aeruginosa rapidly inactivates the adenosine that host cells produce in an HIF-dependent manner, thus depriving the host epithelium of the actions of extracellular adenosine signaling that promote intestinal barrier function during inflammation and hypoxia. ${ }^{62,86-88}$

During infection with group A streptococcus or $P$. aeruginosa, HIF-1 $a$ in immune cells induces inflammation that helps to eliminate the pathogen. ${ }^{37}$ In mice lacking HIF-1 $a$, bactericidal activity is decreased in myeloid cells, and the systemic spread of infection cannot be contained. ${ }^{37}$

\section{CONCLUSIONS}

Hypoxia and inflammation are intertwined at the molecular, cellular, and clinical levels. Oxygen-sensing mechanisms and hypoxia signaling are potential therapeutic targets for the treatment of inflammatory diseases. The value of such approaches could be tested in patients with acute lung injury, myocardial ischemia, inflammatory bowel disease, or cancer. Targeting hypoxia-dependent signaling pathways could also help attenuate organ failure due to ischemia in patients undergoing major surgery or alleviate hypoxia-driven graft inflammation after solid-organ transplantation.

\section{References}

1. Semenza GL. Life with oxygen. Science. 2007; 318:62-4. [PubMed: 17916722]

2. Hackett PH, Roach RC. High-altitude illness. N Engl J Med. 2001; 345:107-14. [PubMed: 11450659]

3. Grocott MPW, Martin DS, Levett DZH, McMorrow R, Windsor J, Montgomery HE. Arterial blood gases and oxygen content in climbers on Mount Everest. N Engl J Med. 2009; 360:140-9. [PubMed: 19129527] 
4. Hartmann G, Tschop M, Fischer R, et al. High altitude increases circulating interleukin-6, interleukin-1 receptor antagonist and C-reactive protein. Cytokine. 2000; 12:246-52. [PubMed: 10704252]

5. Rosenberger P, Schwab JM, Mirakaj V, et al. Hypoxia-inducible factor-dependent induction of netrin-1 dampens inflammation caused by hypoxia. Nat Immunol. 2009; 10:195-202. [PubMed: 19122655]

6. Eckle T, Faigle M, Grenz A, Laucher S, Thompson LF, Eltzschig HK. A2B adenosine receptor dampens hypoxia-induced vascular leak. Blood. 2008; 111:2024-35. [PubMed: 18056839]

7. Eltzschig HK, Ibla JC, Furuta GT, et al. Coordinated adenine nucleotide phosphohydrolysis and nucleoside signaling in posthypoxic endothelium: role of ectonucleotidases and adenosine A2B receptors. J Exp Med. 2003; 198:783-96. [PubMed: 12939345]

8. Thompson LF, Eltzschig HK, Ibla JC, et al. Crucial role for ecto-5'-nucleotidase (CD73) in vascular leakage during hypoxia. J Exp Med. 2004; 200:1395-405. [PubMed: 15583013]

9. Eltzschig HK, Abdulla P, Hoffman E, et al. HIF-1-dependent repression of equilibrative nucleoside transporter (ENT) in hypoxia. J Exp Med. 2005; 202:1493-505. [PubMed: 16330813]

10. Kruger B, Krick S, Dhillon N, et al. Donor Toll-like receptor 4 contributes to ischemia and reperfusion injury following human kidney transplantation. Proc Natl Acad Sci U S A. 2009; 106:3390-5. [PubMed: 19218437]

11. De Perrot M, Sekine Y, Fischer S, et al. Interleukin-8 release during early reperfusion predicts graft function in human lung transplantation. Am J Respir Crit Care Med. 2002; 165:211-5. [PubMed: 11790657]

12. Andrade CF, Kaneda H, Der S, et al. Toll-like receptor and cytokine gene expression in the early phase of human lung transplantation. J Heart Lung Transplant. 2006; 25:1317-23. [PubMed: 17097495]

13. Ye J. Emerging role of adipose tissue hypoxia in obesity and insulin resistance. Int J Obes (Lond). 2009; 33:54-66. [PubMed: 19050672]

14. Karhausen J, Furuta GT, Tomaszewski JE, Johnson RS, Colgan SP, Haase VH. Epithelial hypoxiainducible factor-1 is protective in murine experimental colitis. J Clin Invest. 2004; 114:1098-106. [PubMed: 15489957]

15. Giatromanolaki A, Sivridis E, Maltezos E, et al. Hypoxia inducible factor 1alpha and 2alpha overexpression in inflammatory bowel disease. J Clin Pathol. 2003; 56:209-13. [PubMed: 12610101]

16. Kempf VA, Lebiedziejewski M, Alitalo K, et al. Activation of hypoxia-inducible factor-1 in bacillary angiomatosis: evidence for a role of hypoxia-inducible factor-1 in bacterial infections. Circulation. 2005; 111:1054-62. [PubMed: 15723970]

17. Kaelin WG Jr, Ratcliffe PJ. Oxygen sensing by metazoans: the central role of the HIF hydroxylase pathway. Mol Cell. 2008; 30:393-402. [PubMed: 18498744]

18. Kaelin WG. Von Hippel-Lindau disease. Annu Rev Pathol. 2007; 2:145-73. [PubMed: 18039096]

19. Coleman ML, Ratcliffe PJ. Signalling cross talk of the HIF system: involvement of the FIH protein. Curr Pharm Des. 2009; 15:3904-7. [PubMed: 19671041]

20. Ladroue C, Carcenac R, Leporrier M, et al. PHD2 mutation and congenital erythrocytosis with paraganglioma. N Engl J Med. 2008; 359:2685-92. [PubMed: 19092153]

21. Blouin CC, Page EL, Soucy GM, Richard DE. Hypoxic gene activation by lipopolysaccharide in macrophages: implication of hypoxia-inducible factor 1alpha. Blood. 2004; 103:1124-30. [PubMed: 14525767]

22. Cash TP, Pan Y, Simon MC. Reactive oxygen species and cellular oxygen sensing. Free Radic Biol Med. 2007; 43:1219-25. [PubMed: 17893032]

23. Knowles HJ, Mole DR, Ratcliffe PJ, Harris AL. Normoxic stabilization of hypoxia-inducible factor-1alpha by modulation of the labile iron pool in differentiating U937 macrophages: effect of natural resistance-associated macrophage protein 1. Cancer Res. 2006; 66:2600-7. [PubMed: 16510578]

24. Fraisl P, Mazzone M, Schmidt T, Carmeliet P. Regulation of angiogenesis by oxygen and metabolism. Dev Cell. 2009; 16:167-79. [PubMed: 19217420] 
25. Percy MJ, Furlow PW, Lucas GS, et al. A gain-of-function mutation in the HIF2A gene in familial erythrocytosis. N Engl J Med. 2008; 358:162-8. [PubMed: 18184961]

26. Naugler WE, Karin M. NF-kappaB and cancer-identifying targets and mechanisms. Curr Opin Genet Dev. 2008; 18:19-26. [PubMed: 18440219]

27. Vallabhapurapu S, Karin M. Regulation and function of NF-kappaB transcription factors in the immune system. Annu Rev Immunol. 2009; 27:693-733. [PubMed: 19302050]

28. Pasparakis M. IKK/NF-kappaB signaling in intestinal epithelial cells controls immune homeostasis in the gut. Mucosal Immunol. 2008; 1(Suppl 1):S54-S57. [PubMed: 19079232]

29. Taylor CT. Interdependent roles for hypoxia inducible factor and nuclear factorkappaB in hypoxic inflammation. J Physiol. 2008; 586:4055-9. [PubMed: 18599532]

30. Cummins EP, Berra E, Comerford KM, et al. Prolyl hydroxylase-1 negatively regulates IkappaB kinase-beta, giving insight into hypoxia-induced NFkappaB activity. Proc Natl Acad Sci U S A. 2006; 103:18154-9. [PubMed: 17114296]

31. Tambuwala MM, Cummins EP, Lenihan CR, et al. Loss of prolyl hydroxylase-1 protects against colitis through reduced epithelial cell apoptosis and increased barrier function. Gastroenterology. 2010 Jun 30. (Epub ahead of print).

32. Chen LW, Egan L, Li ZW, Greten FR, Kagnoff MF, Karin M. The two faces of IKK and NFkappaB inhibition: prevention of systemic inflammation but increased local injury following intestinal ischemia-reperfusion. Nat Med. 2003; 9:575-81. [PubMed: 12692538]

33. Bonello S, Zahringer C, BelAiba RS, et al. Reactive oxygen species activate the HIF-1alpha promoter via a functional NFkappaB site. Arterioscler Thromb Vasc Biol. 2007; 27:755-61. [PubMed: 17272744]

34. Rius J, Guma M, Schachtrup C, et al. NF-kappaB links innate immunity to the hypoxic response through transcriptional regulation of HIF-1alpha. Nature. 2008; 453:807-11. [PubMed: 18432192]

35. Kuhlicke J, Frick JS, Morote-Garcia JC, Rosenberger P, Eltzschig HK. Hypoxia inducible factor (HIF)-1 coordinates induction of Toll-like receptors TLR2 and TLR6 during hypoxia. PLoS One. 2007; 2(12):e1364. [PubMed: 18159247]

36. Cramer T, Yamanishi Y, Clausen BE, et al. HIF-1alpha is essential for myeloid cell-mediated inflammation. Cell. 2003; 112:645-57. Erratum, Cell 2003;113:419. [PubMed: 12628185]

37. Peyssonnaux C, Datta V, Cramer T, et al. HIF-1alpha expression regulates the bactericidal capacity of phagocytes. J Clin Invest. 2005; 115:1806-15. [PubMed: 16007254]

38. Nizet V, Johnson RS. Interdependence of hypoxic and innate immune responses. Nat Rev Immunol. 2009; 9:609-17. [PubMed: 19704417]

39. Walmsley SR, Print C, Farahi N, et al. Hypoxia-induced neutrophil survival is mediated by HIF-1 $\{$ alpha\}-dependent NF-\{kappa\}B activity. J Exp Med. 2005; 201:105-15. [PubMed: 15630139]

40. Walmsley SR, Cowburn AS, Clatworthy MR, et al. Neutrophils from patients with heterozygous germline mutations in the von Hippel Lindau protein (pVHL) display delayed apoptosis and enhanced bacterial phagocytosis. Blood. 2006; 108:3176-8. [PubMed: 16809612]

41. Sitkovsky M, Lukashev D. Regulation of immune cells by local-tissue oxygen tension: HIF1 alpha and adenosine receptors. Nat Rev Immunol. 2005; 5:712-21. [PubMed: 16110315]

42. Kojima H, Gu H, Nomura S, et al. Abnormal B lymphocyte development and autoimmunity in hypoxia-inducible factor 1alpha-deficient chimeric mice. Proc Natl Acad Sci U S A. 2002; 99:2170-4. [PubMed: 11854513]

43. Ben-Shoshan J, Afek A, Maysel-Auslender S, et al. HIF-1alpha overexpression and experimental murine atherosclerosis. Arterioscler Thromb Vasc Biol. 2009; 29:665-70. [PubMed: 19251587]

44. Ben-Shoshan J, Maysel-Auslender S, Mor A, Keren G, George J. Hypoxia controls CD4+CD25+ regulatory T-cell homeostasis via hypoxia-inducible factor-1alpha. Eur J Immunol. 2008; 38:2412-8. [PubMed: 18792019]

45. D'Alessio FR, Tsushima K, Aggarwal NR, et al. CD4+CD25+Foxp3+ Tregs resolve experimental lung injury in mice and are present in humans with acute lung injury. J Clin Invest. 2009; 119:2898-913. [PubMed: 19770521] 
46. Deaglio S, Dwyer KM, Gao W, et al. Adenosine generation catalyzed by CD39 and CD73 expressed on regulatory T cells mediates immune suppression. J Exp Med. 2007; 204:1257-65. [PubMed: 17502665]

47. Sitkovsky MV. T regulatory cells: hypoxia-adenosinergic suppression and redirection of the immune response. Trends Immunol. 2009; 30:102-8. [PubMed: 19201652]

48. Colgan SP, Taylor CT. Hypoxia: an alarm signal during intestinal inflammation. Nat Rev Gastroenterol Hepatol. 2010; 7:281-7. [PubMed: 20368740]

49. Furuta GT, Turner JR, Taylor CT, et al. Hypoxia-inducible factor 1-dependent induction of intestinal trefoil factor protects barrier function during hypoxia. J Exp Med. 2001; 193:1027-34. [PubMed: 11342587]

50. Eltzschig HK. Adenosine: an old drug newly discovered. Anesthesiology. 2009; 111:904-15. [PubMed: 19741501]

51. Robinson A, Keely S, Karhausen J, Gerich ME, Furuta GT, Colgan SP. Mucosal protection by hypoxia-inducible factor prolyl hydroxylase inhibition. Gastroenterology. 2008; 134:145-55. [PubMed: 18166352]

52. Cummins EP, Seeballuck F, Keely SJ, et al. The hydroxylase inhibitor dimethyloxalylglycine is protective in a murine model of colitis. Gastroenterology. 2008; 134:156-65. [PubMed: 18166353]

53. Taylor CT, Colgan SP. Hypoxia and gastrointestinal disease. J Mol Med. 2007; 85:1295-300. [PubMed: 18026919]

54. Ohta A, Sitkovsky M. Role of G-protein-coupled adenosine receptors in down-regulation of inflammation and protection from tissue damage. Nature. 2001; 414:916-20. [PubMed: 11780065]

55. Thiel M, Chouker A, Ohta A, et al. Oxygenation inhibits the physiological tissue-protecting mechanism and thereby exacerbates acute inflammatory lung injury. PLoS Biol. 2005; 3(6):e174. [PubMed: 15857155]

56. Eckle T, Grenz A, Laucher S, Eltzschig HK. A2B adenosine receptor signaling attenuates acute lung injury by enhancing alveolar fluid clearance in mice. J Clin Invest. 2008; 118:3301-15. [PubMed: 18787641]

57. Reutershan J, Vollmer I, Stark S, Wagner R, Ngamsri KC, Eltzschig HK. Adenosine and inflammation: CD39 and CD73 are critical mediators in LPS-induced PMN trafficking into the lungs. FASEB J. 2009; 23:473-82. [PubMed: 18838482]

58. Schingnitz U, Hartmann K, Macmanus CF, et al. Signaling through the A2B adenosine receptor dampens endotoxin-induced acute lung injury. J Immunol. 2010; 184:5271-9. [PubMed: 20348420]

59. Eltzschig HK, Kohler D, Eckle T, Kong T, Robson SC, Colgan SP. Central role of Sp1-regulated CD39 in hypoxia/ischemia protection. Blood. 2009; 113:224-32. [PubMed: 18812468]

60. Sitkovsky MV, Lukashev D, Apasov S, et al. Physiological control of immune response and inflammatory tissue damage by hypoxia-inducible factors and adenosine A2A receptors. Annu Rev Immunol. 2004; 22:657-82. [PubMed: 15032592]

61. Friedman DJ, Kunzli BM, A-Rahim YI, et al. CD39 deletion exacerbates experimental murine colitis and human polymorphisms increase susceptibility to inflammatory bowel disease. Proc Natl Acad Sci U S A. 2009; 106:16788-93. [PubMed: 19805374]

62. Synnestvedt K, Furuta GT, Comerford KM, et al. Ecto-5_-nucleotidase (CD73) regulation by hypoxia-inducible factor-1 mediates permeability changes in intestinal epithelia. J Clin Invest. 2002; 110:993-1002. [PubMed: 12370277]

63. Eckle T, Kohler D, Lehmann R, El Kasmi KC, Eltzschig HK. Hypoxia-inducible factor-1 is central to cardioprotection: a new paradigm for ischemic preconditioning. Circulation. 2008; 118:166-75. [PubMed: 18591435]

64. Morote-Garcia JC, Rosenberger P, Kuhlicke J, Eltzschig HK. HIF-1-dependent repression of adenosine kinase attenuates hypoxia-induced vascular leak. Blood. 2008; 111:5571-80. [PubMed: 18309031]

65. Morote-Garcia JC, Rosenberger P, Nivillac NM, Coe IR, Eltzschig HK. Hypoxia-inducible factordependent repression of equilibrative nucleoside transporter 2 attenuates mucosal inflammation during intestinal hypoxia. Gastroenterology. 2009; 136:607-18. [PubMed: 19105964] 
66. Eckle T, Krahn T, Grenz A, et al. Cardioprotection by ecto-5'-nucleotidase (CD73) and A2B adenosine receptors. Circulation. 2007; 115:1581-90. [PubMed: 17353435]

67. Kong T, Westerman KA, Faigle M, Eltzschig HK, Colgan SP. HIF-dependent induction of adenosine A2B receptor in hypoxia. FASEB J. 2006; 20:2242-50. [PubMed: 17077301]

68. Kohler D, Eckle T, Faigle M, et al. CD39/ectonucleoside triphosphate diphosphohydrolase 1 provides myocardial protection during cardiac ischemia/reperfusion injury. Circulation. 2007; 116:1784-94. Erratum, Circulation 2007;116(18):e514. [PubMed: 17909107]

69. Grenz A, Osswald H, Eckle T, et al. The reno-vascular A2B adenosine receptor protects the kidney from ischemia. PLoS Med. 2008; 5(6):e137. [PubMed: 18578565]

70. Louis NA, Hamilton KE, Kong T, Colgan SP. HIF-dependent induction of apical CD55 coordinates epithelial clearance of neutrophils. FASEB J. 2005; 19:950-9. [PubMed: 15923405]

71. Semenza GL. Targeting HIF-1 for cancer therapy. Nat Rev Cancer. 2003; 3:721-32. [PubMed: 13130303]

72. Nanni S, Benvenuti V, Grasselli A, et al. Endothelial NOS, estrogen receptor beta, and HIFs cooperate in the activation of a prognostic transcriptional pattern in aggressive human prostate cancer. J Clin Invest. 2009; 119:1093-108. [PubMed: 19363294]

73. Kaelin WG Jr. The von Hippel-Lindau tumour suppressor protein: O2 sensing and cancer. Nat Rev Cancer. 2008; 8:865-73. [PubMed: 18923434]

74. Liao D, Johnson RS. Hypoxia: a key regulator of angiogenesis in cancer. Cancer Metastasis Rev. 2007; 26:281-90. [PubMed: 17603752]

75. De Bock K, De Smet F, Leite De Oliveira R, Anthonis K, Carmeliet P. Endothelial oxygen sensors regulate tumor vessel abnormalization by instructing phalanx endothelial cells. J Mol Med. 2009; 87:561-9. [PubMed: 19455291]

76. Jain RK. Normalization of tumor vasculature: an emerging concept in antiangiogenic therapy. Science. 2005; 307:58-62. [PubMed: 15637262]

77. Mazzone M, Dettori D, Leite de Oliveira R, et al. Heterozygous deficiency of PHD2 restores tumor oxygenation and inhibits metastasis via endothelial normalization. Cell. 2009; 136:839-51. [PubMed: 19217150]

78. Jain RK. A new target for tumor therapy. N Engl J Med. 2009; 360:2669-71. [PubMed: 19535806]

79. Semenza GL. Defining the role of hypoxia-inducible factor 1 in cancer biology and therapeutics. Oncogene. 2010; 29:625-34. [PubMed: 19946328]

80. Haeberle HA, Durrstein C, Rosenberger P, et al. Oxygen-independent stabilization of hypoxia inducible factor (HIF)-1 during RSV infection. PLoS One. 2008; 3(10):e3352. [PubMed: 18839041]

81. Hartmann H, Eltzschig HK, Wurz H, et al. Hypoxia-independent activation of HIF-1 by enterobacteriaceae and their siderophores. Gastroenterology. 2008; 134:756-67. [PubMed: 18325389]

82. Fraisl P, Aragones J, Carmeliet P. Inhibition of oxygen sensors as a therapeutic strategy for ischaemic and inflammatory disease. Nat Rev Drug Discov. 2009; 8:139-52. [PubMed: 19165233]

83. Aragones J, Fraisl P, Baes M, Carmeliet P. Oxygen sensors at the crossroad of metabolism. Cell Metab. 2009; 9:11-22. [PubMed: 19117543]

84. Ripoli M, D’Aprile A, Quarato G, et al. Hepatitis C virus-linked mitochondrial dysfunction promotes hypoxia-inducible factor 1 alpha-mediated glycolytic adaptation. J Virol. 2010; 84:64760. [PubMed: 19846525]

85. Werth N, Beerlage C, Rosenberger C, et al. Activation of hypoxia inducible factor 1 is a general phenomenon in infections with human pathogens. PLoS One. 2010; 5(7):e11576. [PubMed: 20644645]

86. Patel NJ, Zaborina O, Wu L, et al. Recognition of intestinal epithelial HIF-1alpha activation by Pseudomonas aeruginosa. Am J Physiol Gastrointest Liver Physiol. 2007; 292:G134-42. [PubMed: 16901993]

87. Hart ML, Henn M, Kohler D, et al. Role of extracellular nucleotide phosphohydrolysis in intestinal ischemia-reperfusion injury. FASEB J. 2008; 22:2784-97. [PubMed: 18353866] 
88. Hart ML, Jacobi B, Schittenhelm J, Henn M, Eltzschig HK. A2B adenosine receptor signaling provides potent protection during intestinal ischemia/reperfusion injury. J Immunol. 2009; 182:3965-8. [PubMed: 19299692] 


\section{Inflammation in Hypoxic Conditions \\ Hypoxia in Inflammatory Conditions}

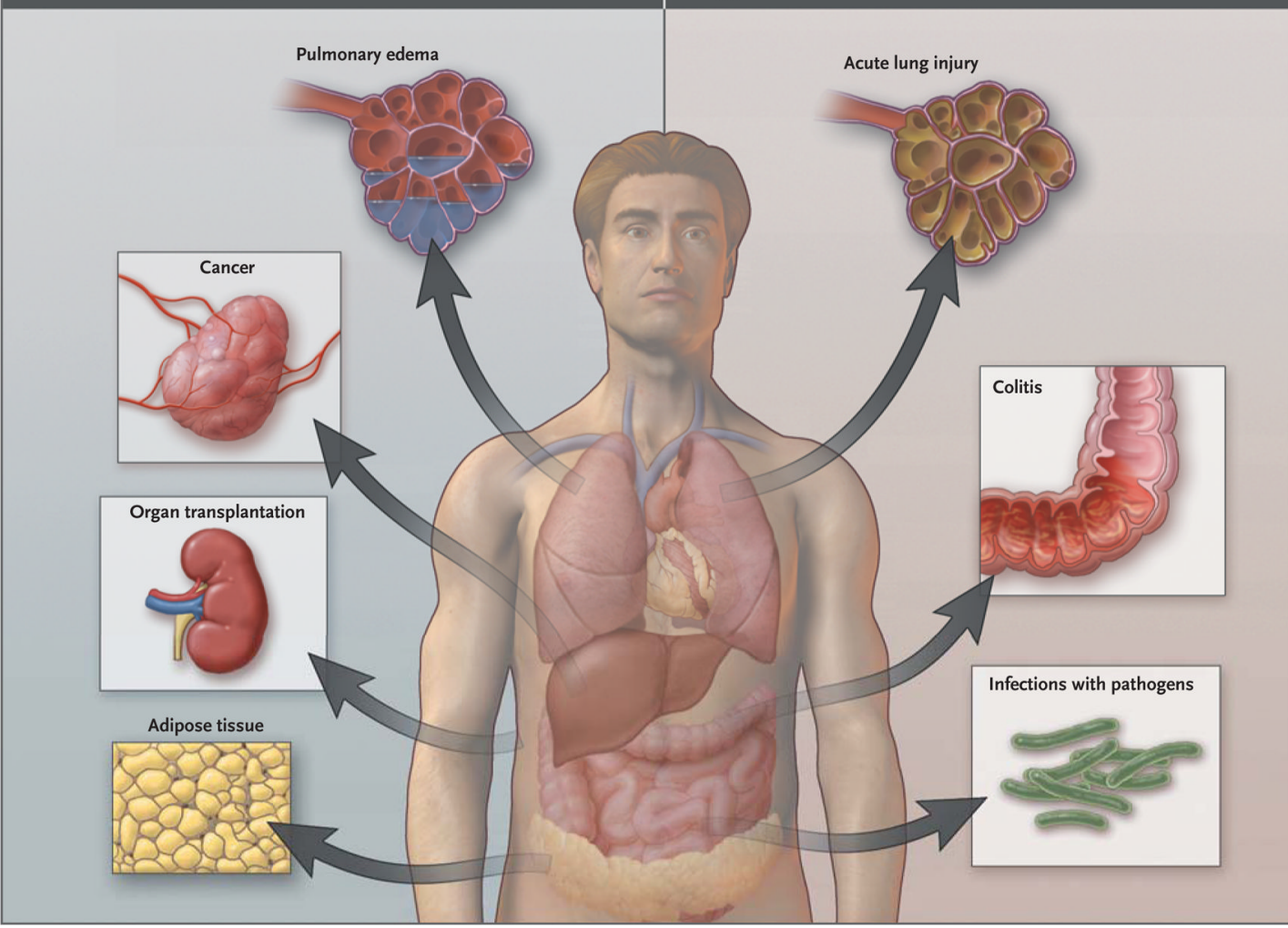

Figure 1. Links between Hypoxia and Inflammation

Shown is an overview of clinical conditions characterized primarily by tissue hypoxia that causes inflammatory changes (left) and inflammatory diseases leading to tissue hypoxia (right). 


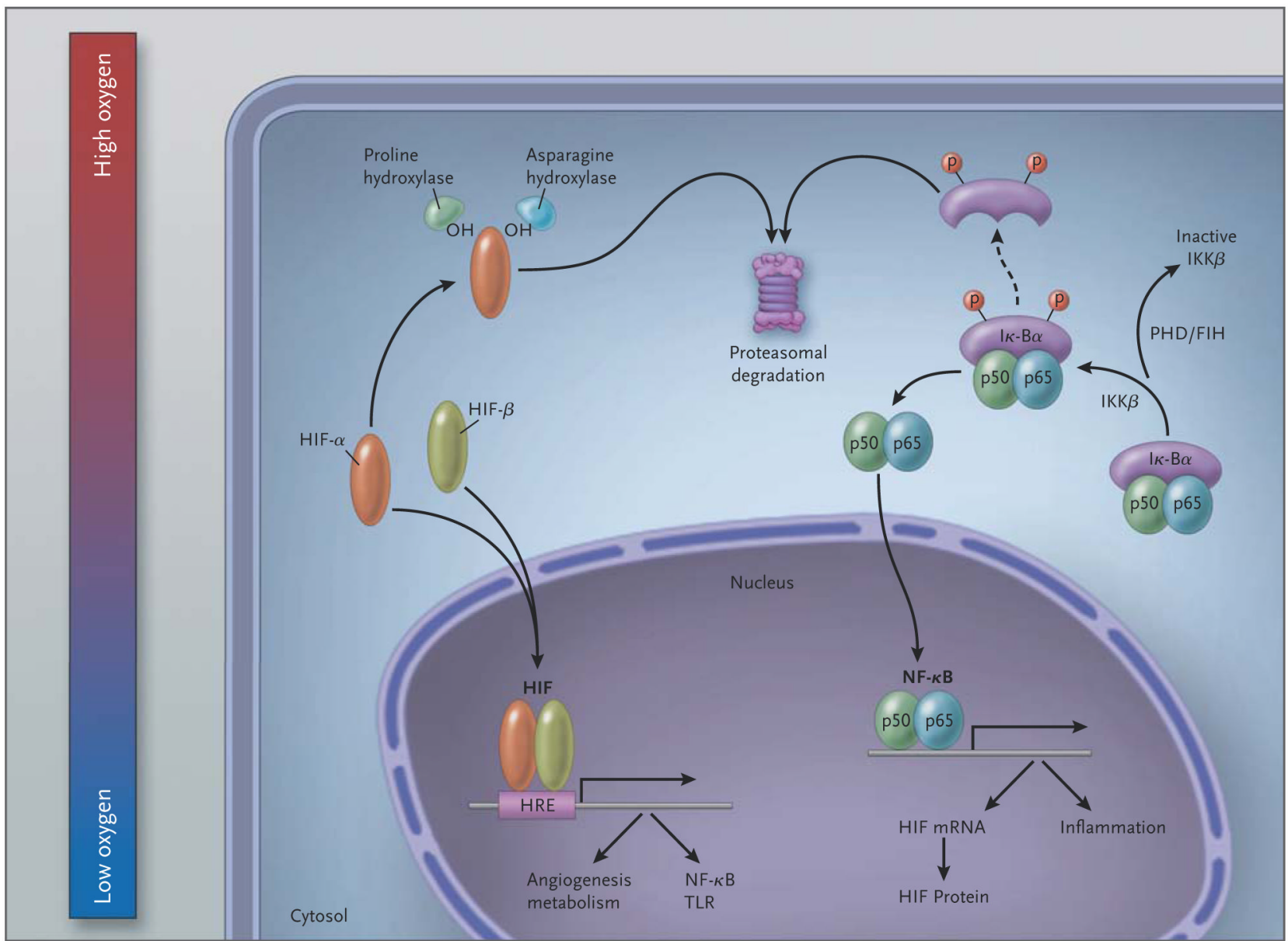

Figure 2. Schematic Overview of the Molecular Interaction between the HIF and (Canonical) NF- $\kappa$ B Pathways

In hypoxic conditions (left), hypoxia-inducible factor (HIF) $a$ and HIF- $\beta$ subunits translocate to the nucleus, where they bind as heterodimers to a hypoxia response promoter element (HRE), inducing transcription of numerous genes, including those of nuclear factor $\kappa \mathrm{B}(\mathrm{NF}-\kappa \mathrm{B})$ and toll-like receptors (TLRs). In normoxia, HIF- $a$ is hydroxylated by prolyl hydroxylases (PHDs) and factor-inhibiting HIF (FIH) and is thereby targeted for proteasomal degradation (in the case of PHDs) or rendered transcriptionally less active (in the case of FIH; not shown here). In resting cells (right), NF- $\kappa \mathrm{B}$, a heterodimer consisting of p50 and p65 subunits, is inactive in the cytosol because it is associated with nuclear factor of kappa light polypeptide gene enhancer in $\mathrm{B}$ cells alpha $(\mathrm{I} \kappa \mathrm{B} \alpha)$, a regulatory component of $\mathrm{NF}-\kappa \mathrm{B}$. At the time of cellular activation, the beta subunit of the I $\kappa \mathrm{B}$ kinase complex $(\mathrm{IKK} \beta)$ phosphorylates the inhibitor $\mathrm{I} \kappa \mathrm{B} a$, which thereby becomes degraded and liberates $\mathrm{NF}-\kappa \mathrm{B}$ for translocation in the nucleus, where it can activate the transcription of inflammatory genes as well as of HIF (genes involved in tissue protection and homeostasis are not shown). PHDs and FIH regulate $\mathrm{NF}-\kappa \mathrm{B}$ activation by controlling the activity of $\mathrm{IKK} \beta$. 


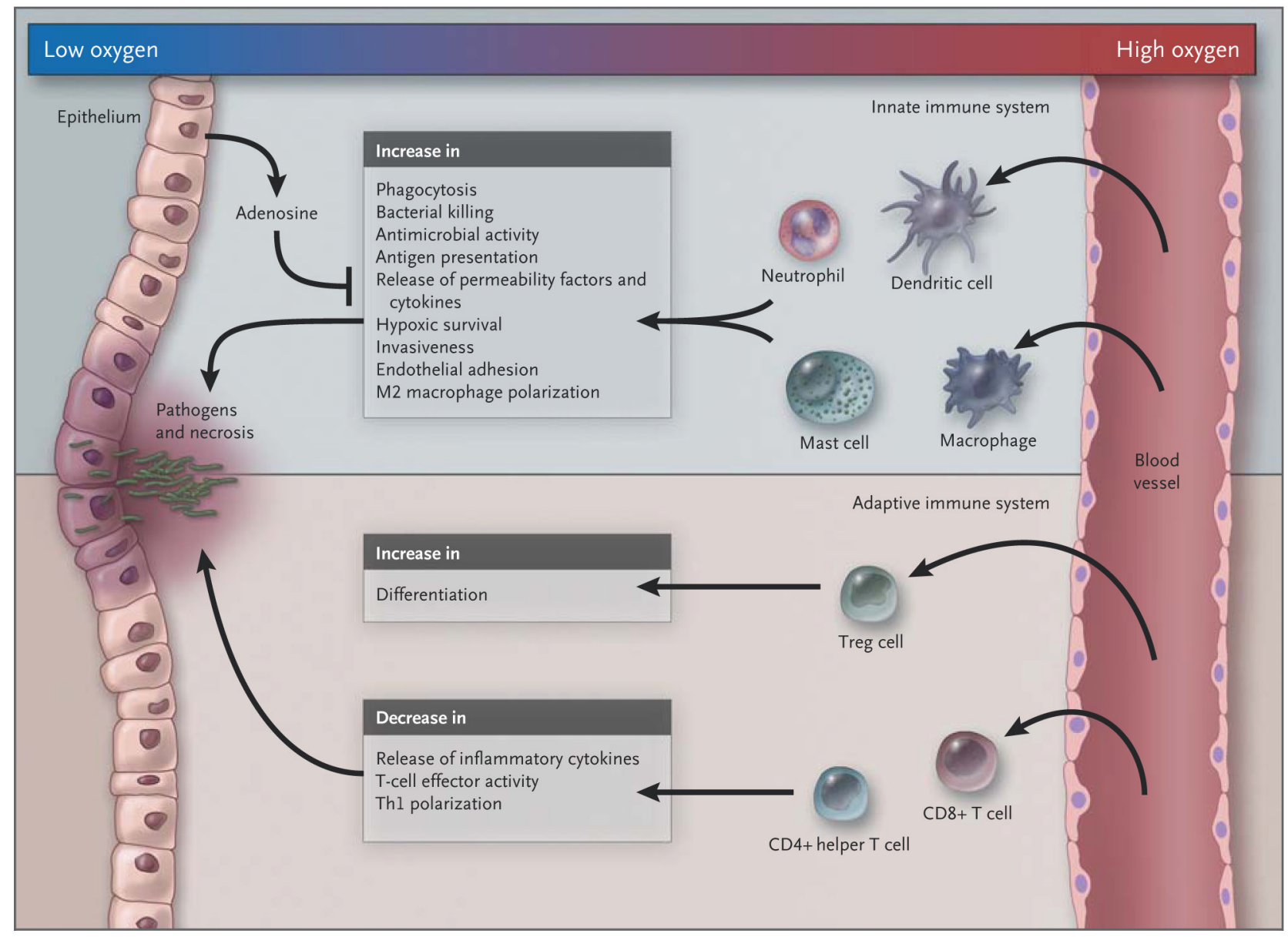

Figure 3. Influence of Hypoxia on the Innate and Adaptive Immune Systems

In the example shown in this schematic overview, the epithelium (left) is breached by invading pathogens, leading to tissue damage; as a result, innate immune cells mount a host defense response, which is amplified by recruited adaptive immune cells. In general, hypoxia amplifies the activity of innate immune cells while suppressing the response of the adaptive immune system, in part by promoting differentiation of regulatory $\mathrm{T}$ cells and negatively regulating the function of CD4+ helper $\mathrm{T}(\mathrm{Th})$ cells and $\mathrm{CD} 8+$ cytotoxic $\mathrm{T}$ cells and the polarization of type $1 \mathrm{Th}$ (Th1) cells. By negatively regulating adaptive immunity, hypoxia prevents excessive activation of the immune host defense, which might otherwise lead to collateral tissue damage. 


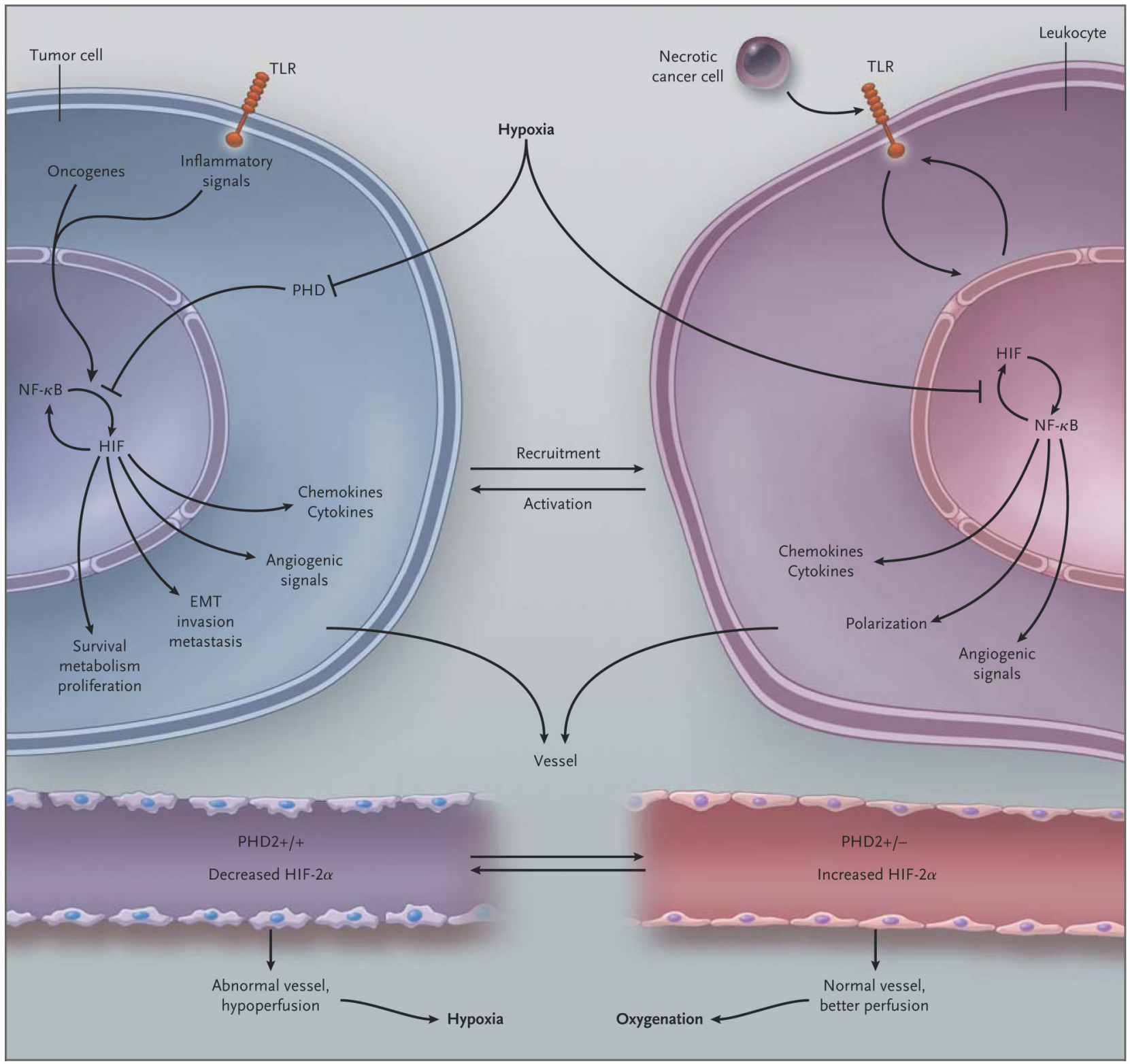

Figure 4. Schematic Overview of the Link between Hypoxia and Inflammation in Cancer In tumor cells, oncogenes, inflammatory signals (mediated in part through toll-like receptors [TLRs]), and hypoxia activate nuclear factor $\kappa \mathrm{B}(\mathrm{NF}-\kappa \mathrm{B})$ and hypoxia-inducible factor (HIF) $1 a$ (which activate each other). These factors induce a gene program that recruits and activates leukocytes (through release of chemokines and cytokines), stimulates angiogenesis and the formation of an abnormal vasculature and endothelium (through release of angiogenic signals), and increases tumor-cell invasion, metastasis, epithelial-tomesenchymal transition (EMT), survival, proliferation, and metabolic reprogramming. In leukocytes, hypoxia also activates NF- $\kappa \mathrm{B}$ and HIF- $1 a$; endogenous ligands, released from necrotic cancer cells, activate TLRs upstream of NF- $\kappa$ B and HIF- $1 a$, and HIF- $1 a$ upregulates TLR expression. A resultant gene-expression profile leads to the production of cytokines and angiogenic signals and skews their polarization phenotype. Tumor vessels with two prolyl hydroxylase (PHD) domain 2 (PHD2) alleles have an abnormal endothelium, are hypoperfused, and cause tumor hypoxia, which fuels tumor-cell 
invasiveness and metastasis. In contrast, tumor vessels lacking one PHD2 allele have increased HIF- $2 a$ levels, which result in an up-regulation of factors that counteract the development of tumor endothelial abnormalities; this, in turn, results in improved tumorvessel perfusion and oxygenation and, secondarily, reduced metastasis. 